\title{
Correction to: Learning orientations of IT higher education students in UAE University
}

\author{
Nabeel Al-Qirim ${ }^{1}$ - Ali Tarhini ${ }^{2}$ - Kamel Rouibah ${ }^{3}$. \\ Mohamed Adel Serhani ${ }^{1}$ • Aishah Rashid Yammahi ${ }^{1}$. \\ Maraim Ahmed Yammahi ${ }^{1}$
}

Published online: 10 April 2018

(C) Springer Science+Business Media, LLC, part of Springer Nature 2018

Correction to: Educ Inf Technol (2018) 23:129-142

https://doi.org/10.1007/s10639-017-9589-y

The authors would like to note that one of the co-author's names was displayed incorrectly. Not Serhani Mohamd, but Mohamed Adel Serhani co-authored this article as correctly shown above.

The online version of the original article can be found at https://doi.org/10.1007/s10639-017-9589-y

Nabeel Al-Qirim

nalqirim@uaeu.ac.ae

Ali Tarhini

alitarhini@squ.edu.om

Kamel Rouibah

krouibah@cba.edu.kw

1 College of Information Technology, United Arab Emirates University, Al-Ain, United Arab Emirates

2 Sultan Qaboos University, Muscat, Oman

3 Kuwait University, Kuwait City, Kuwait 